\title{
Reforma Judicial Tribunales de Familia: IV Etapa Parque de los Reyes
}

\author{
Bruno Giliberto R. / Profesor Guía: Eduardo Lyon R.
}

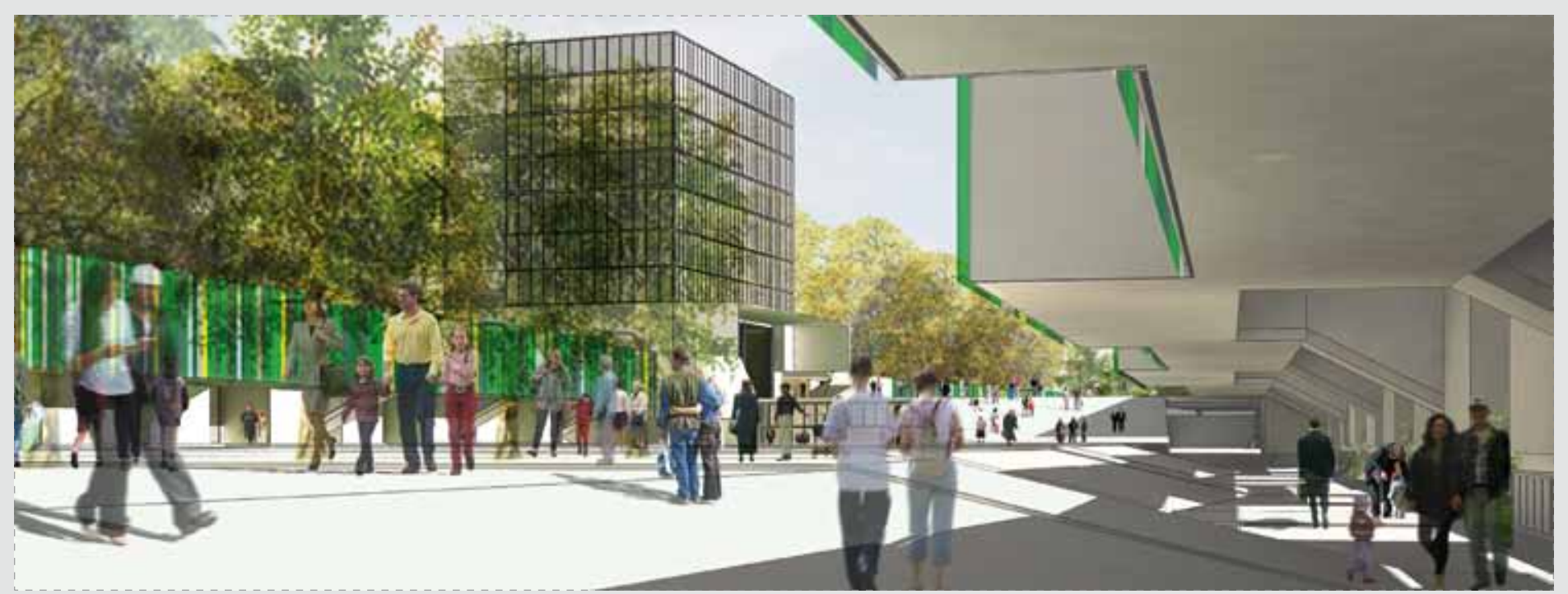

La creación de los nuevos Tribunales de Familia y su reciente puesta en marcha ha dejado entrever algunos problemas en cuanto a la aplicación de la Reforma Judicial. Las relaciones espaciales y la solución propuesta no guardan relación con los procesos de una causa y menos con los requerimientos de la familia.

Es por esto que el presente proyecto plantea una propuesta nueva, que busca denotar y dar solución del problema desde un punto de vista arquitectónico. Debido a la importancia estratégica, política y económica de la ciudad de Santiago, es que el «Núcleo para la Familia» a desarrollar se ubica en la capital. Particularmente en la IV etapa del Parque de los Reyes, comuna de Quinta Normal. La relación con el paisaje, la inserción dentro del parque es esencial para entender las relaciones que se buscan generar entre los procesos judiciales y la recreación familiar.

El proyecto busca posicionarse como articulación entre el parque y la ciudad, esta última entendida no sólo como lo construido, sino que también como un sistema de relaciones entre diferentes elementos que constituyen el paisaje. Es fundamental entender que la búsqueda está dirigida en atender e involucrar a la familia y no a proyectar exclusivamente un edificio apto para dictaminar sentencia frente a problemas legales de la misma.

Se plantea generar una nueva imagen para la justicia de familia, más cercana al ciudadano, buscando cuestionar la estructura actual de los Tribunales de Familia, tanto en sus relaciones con la ciudad como consigo misma.
El cambio en cuanto a la modernización de los procesos en el juicio de familia no sólo deben repercutir en la dotación de personal en los Juzgados, si no que éstos a su vez deben ser reflejados en la manera de posicionarse en la ciudad y abrirse a la misma. La ruptura del edificio clásico del poder legislativo es fundamental para proyectar una modernización a nivel Judicial.

En definitiva el proyecto busca materializar la importancia de la familia en la estructuración de una sociedad, ubicándose así en un lugar protagónico dentro de los flujos del gran Santiago, y generando a partir del mismo, un ejemplo para los futuros núcleos de justicia a lo largo del país. 


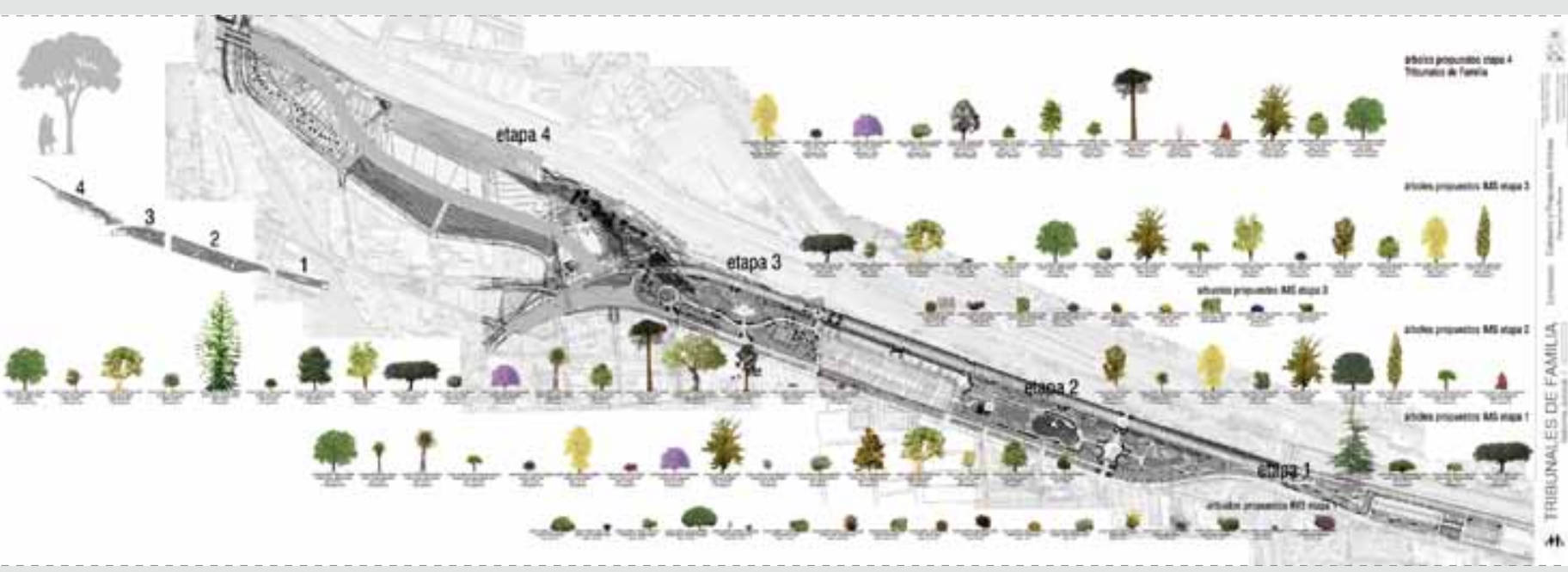

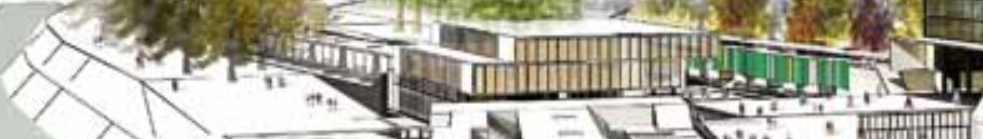
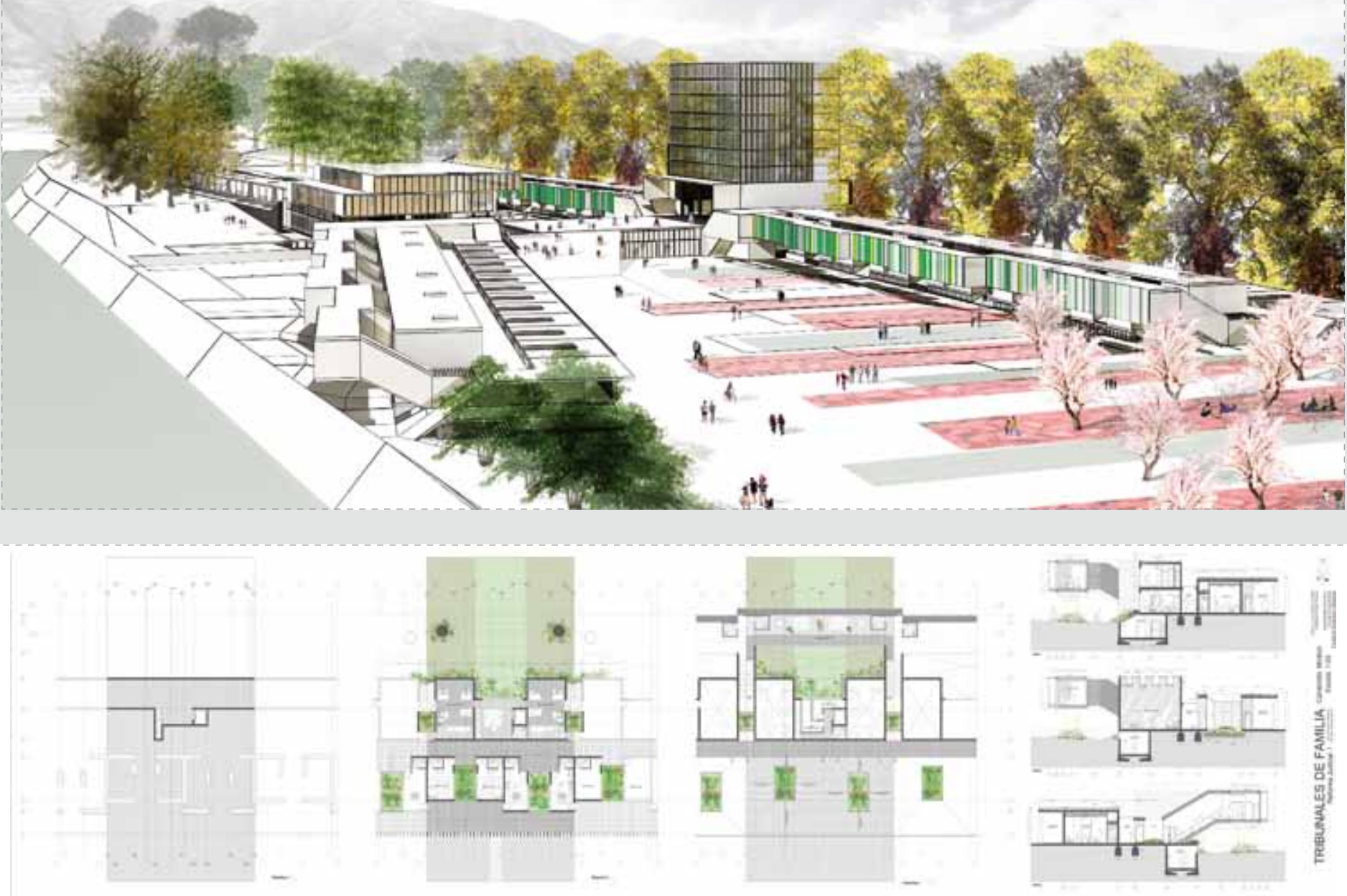